\title{
Influence of scent deposits on flower choice: experiments in an artificial flower array with bumblebees*
}

\author{
Sebastian WITJES, Thomas ELTZ \\ Department of Neurobiology, Sensory Ecology Group, University of Düsseldorf, Universitätstr. 1, \\ 40225 Düsseldorf, Germany
}

Received 27 December 2005 - Revised 28 March 2006 - Accepted 13 April 2006

\begin{abstract}
Foraging bumblebees leave chemical substances when visiting flowers and the detection of these "scent marks" improves their foraging efficiency. Whereas laboratory studies found that scent-marks convey attraction to food sources, all field studies found foragers to be repelled by recently visited flowers. In this study we aim to resolve this conflict by implementing near-natural reward dynamics in a laboratory feeder array. When feeders were filled with small, non-replenished amounts of reward, worker bumblebees (Bombus terrestris) avoided revisiting the depleted feeders. As evidenced by a "corolla" replacement experiment, feeder discrimination was based on the perception of chemical cues deposited during previous visits. Pentane extracts of bumblebee tarsi acted as a repellent when applied to glass corollas, whereas pure pentane did not. We suggest that scent-marks are simple cues inherent to footprints and emphasize the importance of context to how these cues are interpreted by foraging bees.
\end{abstract}

\section{flower discrimination / repellent scent marks / chemical cue / signal / bumble bees / Bombus}

\section{INTRODUCTION}

Foraging bumblebees face a heterogeneous environment in which the amount of reward provided by individual flowers is difficult to predict. Within a given plant species the quality and quantity of nectar varies depending on the location of the plant individual, age of the plant, position of the flower on the plant, age of the flower and the time of day (Klinkhamer and van der Lugt, 2004; Leiss and Klinkhamer, 2005). In addition, reward distribution is influenced markedly by the flower visitors themselves, both within and among patches (Wetherwax, 1986; Zimmerman, 1981). The existing variability in nectar standing crops represents a formidable challenge to individual bumblebees, whose foraging behaviour has evolved not only to meet their own energetic requirements but also to provide for their colony (Heinrich,

Corresponding author: T. Eltz, eltz@uni-duesseldorf.de

* Manuscript editor: Marla Spivak 1979a). In natural flower patches, bumblebees frequently can be observed to hover in front of individual flowers or inflorescences, but then depart without actually probing for nectar. The flowers which bumblebees reject contain on average less nectar than flowers which are being probed (Heinrich, 1979b; Marden, 1984; Wetherwax, 1986). Thus it appears that bumblebees use some means of remote sensing for their decision on what flower to probe. Possible mechanisms include direct detection of the nectar by visual (Kevan, 1976; Thorp et al., 1975, 1976) or olfactory (Raguso, 2004) cues. However, many bumblebee-visited plant species have flowers in which nectar is concealed at the base of deep corolla tubes, which makes direct assessment of nectar volume problematic. In such cases more accurate information about reward levels may be obtained by using indirect cues. Several studies have emphasized that bees use scent-marks deposited on the flower by themselves or by conspecifics to identify the availability of a 
reward. With variable stringency such effects have been demonstrated in honeybees (Giurfa, 1993; Giurfa and Nuñez, 1992), bumblebees (Cameron, 1981; Goulson et al., 1998, 2000; Schmitt et al., 1991), stingless bees (Hrncir et al., 2004; Jarau et al., 2004; Schmidt et al., 2005), and solitary bees (Gawleta et al., 2005; Gilbert et al., 2001; Goulson et al., 2001). By interpreting such scent-marks bees are able to reduce the time required to search for a reward and thus increase their overall foraging efficiency (Giurfa, 1993; Schmitt and Bertsch, 1990; Stout et al., 1998).

In bumblebees the glandular origin of the deposited substances is unclear, and it is an open question whether scent-marking is an active process. Insects are known to leave lipid footprints wherever they walk, and those footprints may be used as cues by subsequent visitors (Federle et al., 2002; Schmidt et al., 2005). Several studies have investigated bumblebee scent-marks and their effect on foraging efficiency. There is one striking difference concerning the results of these experiments. In field experiments foragers have always been found to be repelled by recently visited (scent-marked) flowers (Goulson et al., 1998, 2000; Stout et al., 1998; Gawleta et al., 2005), whereas in laboratory experiments an attractant effect has been found (Cameron, 1981; Schmitt and Bertsch, 1990; Schmitt et al., 1991). The present study aims to resolve this conflict. In accordance with an argument made by Goulson et al. (2000), we hypothesize that the origin of the discrepancy is based on unnatural reward conditions in the laboratory studies. Under most natural conditions flowers contain only minimal amounts of nectar, which are easily extracted by foragers during a single visit. Since nectar secretion rates are low in nature (Stout and Goulson, 2001), a fresh scent-mark of another bee spells "empty". Thus, in the natural context, bees learn to avoid recently visited (scent-marked) flowers. In contrast, when rewarding feeders were presented in laboratory experiments, they carried a continuous reward or were immediately replenished (Cameron, 1981; Schmitt and Bertsch, 1990; Schmitt et al., 1991). In this context foragers were encouraged to detect and revisit scent-marked feeders, while at the same time neglecting unmarked feeders. While these results confirmed traditional views of "attractant scentmarks" in social bees, they were derived from an unnatural situation. In the present laboratory study we modelled the reward dynamics much more closely to the natural situation, with feeders carrying only tiny amounts of nectar that, once exploited, were not replenished during an individual foraging bout. We hypothesized that foragers would now avoid recently visited flowers and that this discrimination enhances their foraging efficiency. Furthermore, we tested whether flower discrimination does indeed depend on recognition of deposited substances, and whether the discrimination ability increases with growing experience.

\section{MATERIALS AND METHODS}

Colonies of Bombus terrestris (Koppert Biological Systems) were fed with sugar-water in permanently rewarding feeders (carrying yellow glass corollas identical to those of the test flowers described below) in a feeding box connected to the main nest box. Individual foragers were marked and later introduced into a test cage measuring $60 \times 65 \times 85 \mathrm{~cm}$ and covered with mosquito mesh. One end of the cage was fitted with a disk made of grey PVC (diameter $60 \mathrm{~cm}$ ) which could be rotated around its central axis and had fittings for up to 21 artificial flowers, spaced more or less uniformly over the entire disk area. The corolla of an individual feeder (Fig. 1) was a tube of yellow quartzglass $4 \mathrm{~cm}$ in length and $2.1 \mathrm{~cm}$ in diameter. It sat on a short Plexiglas cylinder in which a $1.5 \mathrm{~mm}$ bore had been drilled for the sugar-water reward. At the rear end of the cylinder the bore widened to $3 \mathrm{~mm}$. Before each trial the narrow front ends of the bores were filled with $2 \mu \mathrm{L}$ of a $50 \%$ sugar-water reward. The rear ends, being well out of the reach of the bees' proboscises, received another droplet of the same solution. This was supposed to maintain unaltered odour and humidity even after the sugar-water reward had been collected by the foraging bumblebee. After a bumblebee had been introduced into the test arena its behaviour was recorded with the help of the software clbehave (Compulights $\mathrm{GmbH}$, Mönchengladbach). We logged the sequence of the approached (numbered) feeders and registered whether an approached feeder was visited 


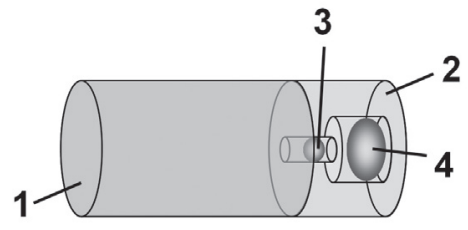

Figure 1. Schematic view of an artificial flower with detachable quartz-glass corolla (1) sitting on a Plexiglas cylinder (2) with a small bore drilled in the front end to receive $2 \mu \mathrm{L}$ of sugar water reward (3) as well as a larger rear-end bore to receive an additional droplet of sugar water (4), which could not be reached by foraging bumblebees.

or rejected. A feeder was defined as being visited if a bee crawled completely into the glass corolla, assuming a position that would allow probing (the proboscis extension could not be directly observed from the outside). Rejection included all approaches that were not followed by landing or, if a landing took place, it was brief and not followed by in-depth inspection of the flower. During data analysis we were able to establish whether a given visit was actually rewarded or not, depending on whether it was the first visit to that feeder during a particular trial.

\subsection{Experiment 1}

We tested whether foragers avoided feeders recently depleted by themselves in order to increase their foraging efficiency, and whether this ability improved with growing experience. Bumblebees foraged on a disk fitted with 21 artificial flowers. Up to 70 approaches were recorded per individual trial and each individual completed four consecutive trials. Following each feeder visit the disk was rotated to exclude the possibility that bees memorized the position of visited feeders. After each trial the bumblebees were released into the colony to deliver the collected sugar-water. The glass corollas were rinsed in acetone, the Plexiglas tubes swabbed with hexane. To analyse the efficiency of exploitation we plotted the number of visits required to receive a given number of rewards (Fig. 2) and compared the observed performance to the performance expected by chance, e.g. in the case that every corolla was selected by random choice. We used the sign-test (STATISTICA 6.0) to test for differences between the observed number of visits necessary to receive

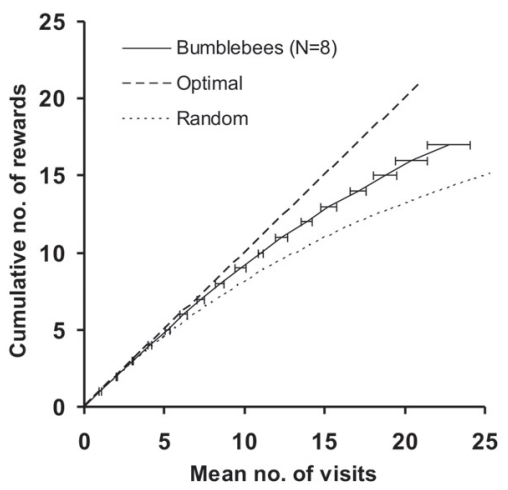

Figure 2. Foraging efficiency of worker bumblebees in a rotating feeder array. The curve shows the mean number (+/- standard deviation) of visits necessary to receive a certain (cumulative) number of rewards. Not that bumblebees were not perfect foragers, but performed better than expected in the case of random choice. Data from all trials pooled for individual bees.

15 rewards and the expected number of visits given that foragers selected flowers randomly. Additionally, we used Repeated-measures ANOVA to test for an effect of experience (No. of trial) on the number of visits individuals required to receive 15 rewards.

\subsection{Experiment 2}

The second experiment was designed to test whether the discrimination against empty feeders was based on the recognition of a chemical cue deposited on the corolla. Again, the bumblebees foraged on an array of 21 artificial flowers. Each bee had to complete 2 trials. The first trial was identical to the trials of experiment 1 and was used as training. The second trial consisted of two different treatments. In one group of bees the experiment was interrupted after 10 rewarded visits by switching off the light in the test chamber. After the visited corollas had been replaced by clean ones the trial continued (Replacement group). In the other group the visited corollas were not replaced but only lifted briefly and then restored (Control group). We used a $\mathrm{t}$-test for independent samples to test for differences between groups in the number of visits necessary to receive 15 rewards.

\subsection{Experiment 3}

To investigate the origin of chemical cues on the feeder corolla we simulated bumblebee footprints 
by applying tarsal pentane extracts to the corolla surface. The experiment consisted of 2 trials per bumblebee, the first being identical to the first trials in experiment 1 and 2 . In the second trial the bumblebees faced 20 rewarding feeders. At ten feeders $5 \mu \mathrm{L}$ of pentane (p.a.) had been applied to each corolla using a micropipette $(0.5-10 \mu \mathrm{L})$. The other ten feeders were treated with the same amount of a tarsal extract in pentane. For production of the extract 5 worker Bombus terrestris were captured in a clean glass vial and freeze killed. The legs were cut at the end of the tibia and extracted in $1 \mathrm{~mL}$ pentane for 30 seconds. We analysed the first 10 rewarded visits and used the Sign-test to test whether individuals visited extract- and pentane-treated flowers with different frequency.

\section{RESULTS}

In experiment 1 , the tested bumblebees quickly learned to avoid previously depleted feeders and thus exploited the array more efficiently than expected by random choice. Figure 2 shows a comparison between the mean foraging performance of the tested bumblebees and the expected performance of a randomly choosing bee. The mean number of visits an individual required to receive 15 rewards was significantly lower than expected by chance when data from all trials were averaged (Sign-test: $\mathrm{N}=8 ; P=0.013$ ). The same result was obtained for trials 1, 2 and 4, when those were analysed separately, but not for trial 3 in which one individual performed worse than when choosing randomly (Signtest: $\mathrm{N}=8 ; P=0.08)$. Learning of the new context (that feeders could be depleted) appeared to take place during the very first flower visit of the first trial. After having depleted the reward the bees repeatedly returned to the bore as if expecting a reward, sometimes turning around several times in the corolla (a similar behaviour was described by Schmitt and Bertsch, 1990). They rarely did this on subsequent visits or during consecutive trials, but quickly left depleted flowers. Additional experience did not further improve overall foraging efficiency; e.g., there was no effect of trial on the number of visits required by an individual to receive 15 rewards (Repeated-measures ANOVA: $\left.\mathrm{N}=8 ; \mathrm{F}_{3,21}=0.078 ; P=0.97\right)$.

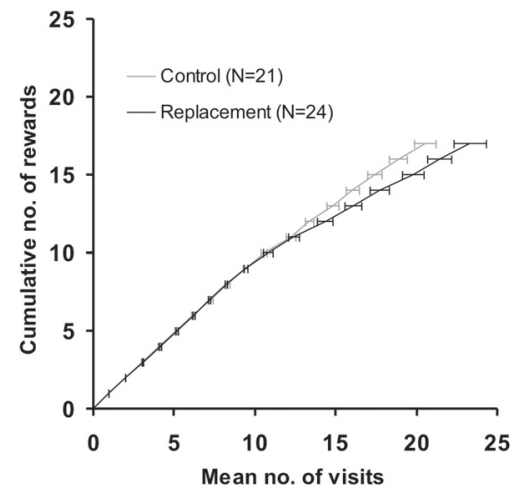

Figure 3. Foraging efficiency of worker bumblebees in a rotating flower array. The curves show the mean number (+/- standard error) of visits necessary to receive a certain (cumulative) number of rewards. In the replacement group visited glass corollas were replaced with clean ones after the first ten successful visits. See text for statistics.

In experiment 2 the intermittent replacement of visited corollas with clean ones ( $\mathrm{Re}$ placement group) significantly increased the number of visits necessary to receive 15 rewards compared to control bees for which the visited corollas had remained in place (Control group) ( $t$-test: $N=45 ; t=2.94 ; \mathrm{df}=40$; $P=0.005)$. The foraging performance of the replacement group decreased markedly after visit No. 11, shortly after the replacement of the corollas (Fig. 3).

Discrimination against chemical cues deposited on visited corollas was confirmed by the results of the third experiment. Here, the bumblebees made significantly fewer visits to the corollas treated with the tarsal extract than to corollas treated with pure pentane (SignTest: $\mathrm{N}=10 ; P<0.01)$. Of the first ten visits, foragers made on average 7.8 visits to flowers treated with pure pentane.

\section{DISCUSSION}

Our results demonstrate that foraging bumblebees deposited chemical cues on visited artificial corollas, and that these cues were recognised by the bees when approaching the same feeders on subsequent occasions. Experimental removal of the deposits by 
corolla replacement prevented discrimination against depleted feeders and reduced overall foraging efficiency. Our findings are direct evidence for the existence of foraging scent-marks in bumblebees. They suggest that context is of prime importance for shaping individual foraging decisions. Given a reward context that imitates the natural situation (small rewards, no immediate refills) the trace of a previous visit acts as a repellent to inhibit further visits, which is in broad agreement with field studies (Goulson et al., 2000; Stout et al., 1998; Gawleta et al., 2005). The importance of context on the interpretation of scent-marks is also reflected by another recent laboratory study (Saleh et al., 2006). When trained bumblebees were presented with two types of artificial flowers that varied in the time required for handling, the rates of rejection were higher in the type that required longer and therefore offered lower net benefit. This suggests that bumblebees can gradually adjust their choice depending on the expected amount of reward within a certain reward context (Saleh et al., 2006).

Are the deposits actively released by bumblebee individuals with the intention of marking depleted flowers (e.g. for themselves), or are the substances unavoidable footprints that may provide simple cues to any forager? Our data do not allow for a distinction to be made between these alternatives. However, we argue that currently the most parsimonious interpretation is to assume that deposits represent cues rather than evolved signals, and that these cues influence behaviour differentially depending on context. Recent studies on other Hymenoptera confirm that "scent-marking" is frequently passive. For example, stingless bees (Nannotrigona testaceicornis) leave chemical traces on Plexiglass on which they have walked, and these substances will later attract other workers when presented in a rewarding context (a permanent feeder) (Schmidt et al., 2005). Similarly, returning yellowjacket foragers follow accumulated footprints of nest mates when these are presented in a "homing context", e.g. within the nest entrance tunnel (Jandt et al., 2005). In bumblebees "scent-marking" probably involves blends of hydrocarbons (mostly uneven-numbered alka- nes and alkenes) which are present in large amounts and similar composition all over the bumblebee cuticle (Goulson et al., 2000; Schmitt et al., 1991; Eltz, 2006). On the tarsi, the primary function of these lipids may be the improvement of attachment pad adhesion to smooth surfaces (Federle et al., 2002), with the secondary spin-off of serving as olfactory cues. Both in the field (Goulson et al., 2000) and in the laboratory (this study) the application of tarsal pentane extracts rendered flowers less attractive to approaching bumblebees in comparison to controls, presumably because the extract application imitated the olfactory trace of a previous visit.

All tested bumblebees had experienced continuously rewarding flowers in their foraging life prior to the experiment (in the feeding box). In experiment 1 we had therefore expected that foragers would show an increasing discrimination against previously visited (marked) feeders from trial to trial, reflecting their increasing experience with discontinuous rewards. However, this was not observed, presumably because learning of the new reward situation took place very early in the first trial. When foragers visited their very first experimental feeder they behaved as if expecting a continuous reward and turned around repeatedly inside the corolla, frequently re-probing the empty bore. As the bees did not leave the respective flower while doing so, these attempts were not counted as repeated visits to the same feeder and, thus, did not affect the measure of foraging efficiency for the first trial. On subsequent visits or during consecutive trials foragers normally left depleted flowers without delay. That bumblebees learned to discriminate against previously visited flowers so quickly may reflect an innate aversion to bumblebee odour while foraging. Perhaps this aversion, potentially adaptive in the natural environment, was simply suppressed by encountering continuous rewards in the feeding box, and later revived during the experiment.

\section{ACKNOWLEDGEMENTS}

We thank Klaus Lunau and the members of the Sensory Ecology Group for stimulating discussions 
and practical help. W. Seidl and the Biology workshop are acknowledged for constructing the experimental setup. Supported by the University of Düsseldorf.

\section{Influence des marques odorantes sur le choix de la fleur par les bourdons : expériences sur fleurs artificielles.}

\section{Bombus / discrimination / marque odorante / message chimique / signal / butinage}

Zusammenfassung - Die Wirkung von Duftmarken auf die Blütenwahl von Hummeln: Ergebnisse eines Laborexperiments an künstlichen Blüten. Hummelarbeiterinnen sammeln Nektar an Blüten einer Vielzahl von Pflanzenarten und individuen, wobei der Nektargehalt einzelner Blüten starken Schwankungen unterliegen kann, nicht zuletzt aufgrund der Aktivität von Blütenbesuchern. In früheren Untersuchungen konnte gezeigt werden, dass Hummeln während des Blütenbesuchs Duftmarken hinterlassen, an Hand derer sie in der Lage sind, zwischen belohnenden und weniger belohnenden Blüten $\mathrm{zu}$ unterscheiden. Allerdings existieren bis heute unterschiedliche Einschätzungen zur Wirksamkeit der Duftmarken. Während Ergebnisse von Freilanduntersuchungen darauf hindeuten, dass Duftmarken immer abweisende Wirkung auf fouragierende Hummeln haben (Goulson et al., 1998, 2000; Stout et al., 1998; Gawleta et al., 2005), wiesen die Ergebnisse von Laborexperimenten auf einen attraktiven Effekt hin (Cameron, 1981; Schmitt and Bertsch, 1990; Schmitt et al., 1991). Die hier vorliegende Untersuchung soll zur Klärung dieser Diskrepanz beitragen und postuliert, dass die Wirkung der Duftmarken vom Belohnungskontext abhängt: In der Natur regenerieren die meisten Blüten ihren Nektar sehr langsam, weshalb sie normalerweise nur geringe Mengen an Nektar enthalten und von Hummeln komplett erschöpft werden können. Hier wird die Duftmarke als Anzeiger kürzlich geleerter Blüten interpretiert und wirkt als Repellent. In Laboruntersuchungen wurden Hummeln dagegen auf kontinuierlich belohnende oder schnell regenerierende Blütenattrappen dressiert, die von einzelnen Individuen nicht erschöpft werden konnten. In diesem Fall erfolgte eine positive Konditionierung auf die Duftmarken und Attraktion. In unseren Laborexperimenten verwendeten wir deshalb zur Nachahmung der natürlichen Situation Blütenattrappen mit nur einmaliger und äußerst geringer $(2 \mu \mathrm{L})$ Zuckerwasserbelohnung. In diesem Belohnungskontext vermieden Hummelarbeiterinnen den nochmaligen Besuch bereits zuvor aufgesuchter (geleerter) Blüten, wie dies auch im Freiland der Fall ist. Die Diskrimination erfolgte hierbei durch einen auf der Korolla zurückgelassen chemischen „Hinweis“, was durch ein Korolla-Austausch-Experiment belegt werden konnte. Die Ergebnisse sprechen dafür, dass es sich bei den Duftmarken um einfache Fußabdrücke handelt, die von Hummeln in Abhängigkeit des Belohnungskontexts unterschiedlich bewertet werden können (,cues rather than signals“).

Blütendiskriminierung / abweisende Duftmarken / chemischer Reiz / Signal / Bombus

\section{REFERENCES}

Cameron S.A. (1981) Chemical signal in bumble bee foraging, Behav. Ecol. Sociobiol. 9, 257-260.

Eltz T. (2006) Tracing pollinator footprints on natural flowers, J. Chem. Ecol. 32, 907-915.

Federle W., Riehle M., Curtis A.S.G., Full R.J. (2002) An integrative study of insect adhesion: Mechanics and wet adhesion of pretarsal pads in ants, Integrative Comp. Biol. 42, 1100-1106.

Gawleta N., Zimmermann Y., Eltz T. (2005) Repellent foraging scent recognition across bee families, Apidologie 36, 325-330.

Gilbert F., Azmeh S., Barnard C., Behnke J., Collins S. A., Hurst J., Shuker D. (2001) Individually recognizable scent marks on flowers made by a solitary bee, Anim. Behav. 61, 217-229.

Giurfa M. (1993) The repellent scent mark of the honeybee Apis melifera ligustica and its role as a communication cue during foraging, Insectes Soc. 40, 59-67.

Giurfa M., Nuñez J.A. (1992) Honeybees mark with scent and reject recently visited flowers, Oecologia 89, 113-117.

Goulson D., Hawson S.A., Stout J.C. (1998) Foraging bumblebees avoid flowers already visited by conspecifics or by other bumblebee species, Anim. Behav. 55, 199-206.

Goulson D., Stout J.C., Langley J., Hughes W.O.H. (2000) Identity and function of scent marks deposited by foraging bumblebees, J. Chem. Ecol. 26, 2897-2911.

Goulson D., Chapman J.W., Hughes W.O.H. (2001) Discrimination of unrewarding flowers by bees; Direct detection of rewards and use of repellent scent marks, J. Insect Behav. 14, 669-678.

Heinrich B. (1979a) Bumblebee economics, Harvard University Press, Cambridge.

Heinrich B. (1979b) Resource heterogeneity and patterns of movement in foraging bumblebees, Oecologia 40, 235-245.

Hrncir M., Jarau S., Zucchi R., Barth F.G. (2004) On the origin and properties of scent marks deposited at the food source by a stingless bee, Melipona seminigra, Apidologie 35, 3-13.

Jandt J.M., Curry C., Hemauer S., Jeanne R.L. (2005) The accumulation of a chemical cue: nest-entrance 
trail in the German yellowjacket, Vespula germanica, Naturwissenschaften 92, 242-245.

Jarau S., Hrncir M., Ayasse M., Schulz C., Francke W., Zucchi R., Barth F.G. (2004) A stingless bee (Melipona seminigra) marks food sources with a pheromone from its claw retractor tendons, J. Chem. Ecol. 30, 793-804.

Kevan P.G. (1976) Fluorescent Nectar, Science 194, 341-342.

Klinkhamer P.G.L., van der Lugt P.P. (2004) Pollinator service only depends on nectar production rates in sparse populations, Oecologia 140, 491-494.

Leiss K.A., Klinkhamer P.G.L. (2005) Spatial distribution of nectar production in a natural Echium vulgare population: Implications for pollinator behaviour, Basic Appl. Ecol. 6, 317-324.

Marden J.H. (1984) Remote perception of floral nectar by bumblebees, Oecologia 64, 232-240.

Raguso R.A. (2004) Why are some floral nectars scented? Ecology 85, 1486-1494.

Saleh N., Ohashi K., Thomson J.D., Chittka L. (2006) Facultative use of the repellent scent mark in foraging bumblebees: complex versus simple? Owers, Anim. Behav. 71, 847-854.

Schmidt V.M., Zucchi R., Barth F.G. (2005) Scent marks left by Nannotrigona testaceicornis at the feeding site: cues rather than signals, Apidologie 36, 285-291.

Schmitt U., Bertsch A. (1990) Do foraging bumblebees scent-mark food sources and does it matter? Oecologia 82, 137-144.

Schmitt U., Lübke G., Francke W. (1991) Tarsal secretion marks food sources in bumblebees (Hymenoptera: Apidae), Chemoecology 2, 35-40.

Stout J.C., Goulson D. (2001) The influence of nectar secretion rates on the responses of bumblebees (Bombus spp.) to previously visited flowers, Behav. Ecol. Sociobiol. 52, 239-246.

Stout J.C., Goulson D., Allen J.A. (1998) Repellent scent-marking of flowers by a guild of foraging bumblebees (Bombus spp.), Behav. Ecol Sociobiol. 43, 317-326.

Thorp R.W., Briggs D.L., Estes J.R., Erickson E.H (1975) Nectar Fluorescence under UltravioletIrradiation, Science 189, 476-478.

Thorp R.W., Briggs D.L., Estes J.R., Erickson E.H (1976) Fluorescent Nectar, Science 194, 342-342.

Wetherwax P.B. (1986) Why do honeybees reject certain flowers? Oecologia 69, 567-570.

Zimmerman M. (1981) Patchiness in the dispersion of nectar resources - probable causes, Oecologia 49, 154-157. 